\title{
Lesões bolhosas numa mulher de pele bronzeada
}

\author{
Bullous lesions in a tanned woman
}

Tatiana Rodrigues, Raquel Cruz, Filipa Sousa, Gorete Jesus.

Serviço de Medicina Interna. Centro Hospitalar do Baixo Vouga E.P.E. Aveiro. Portugal

\section{Resumo}

A porfiria cutânea tarda resulta de uma deficiência enzimática na biossíntese do heme, manifesta-se por alterações cutâneas e está associada a disfunção hepática, podendo ser desencadeada por sobrecarga de ferro. Os autores apresentam o caso de uma doente de 40 anos com porfiria cutânea tarda associada a hemocromatose.

Palavras chave. porfiria cutánea tarda, sobrecarga de hierro, hemocromatosis

\section{Introdução}

A porfiria cutânea tarda (PCT) é o tipo mais frequente de porfiria e resulta de uma deficiência adquirida na actividade enzimática da uroporfirinogénio-descarboxilase (UROD) na biossíntese do heme. Clinicamente manifesta-se por alterações cutâneas como fotossensibilidade, fragilidade cutânea, bolhas, erosões, lesões cicatriciais, mília e hiperpigmentação da pele em áreas expostas ao sol, particularmente face, antebraços, dorso das mãos e pés ${ }^{1,2}$. 0 diagnóstico é confirmado pelo doseamento das porfirinas e seus percursores nas fezes e urina ${ }^{1,2}$. A forma mais comum, tipo I ou esporádica, varia de 72 a $84 \%$ dos casos; cerca de $20 \%$ dos doentes com PCT são heterozigotas para mutações hereditárias da UROD, apresentando formas familiares da doença (Tipo II e Tipo III) com transmissão autossómica dominante de baixa penetrância ${ }^{1,2}$. Tanto na forma esporádica como nas formas familiares a doença manifesta-se quando a UROD hepática é inibida, e a sua actividade reduzida a menos de $20 \%$ do normal ${ }^{2}$. Há formação nas células hepáticas de um inibidor competitivo desta enzima no fígado, por um mecanismo ferro-dependente ${ }^{1}$. Por esta razão é considerada uma doença ferro-dependente, e pelo menos $80 \%$ dos doentes apresenta siderose hepática, embora menos de $20 \%$ tenha o diagnóstico concomitante de hemocromatose ${ }^{3}$.

\section{Caso clínico}

Apresentam os autores o caso de uma doente de 40 anos, sem antecedentes patológicos conhecidos, sem antecedentes familiares relevantes, sem uso de medicação crónica e sem hábitos etílicos, que recorre ao Serviço de Urgência por quadro de lesões cutâneas bolhosas e pruriginosas no dorso das mãos e antebraços (Figura 1), associadas a hiperpigmentação da face (Figura 2), com evolução de 6 meses. Ao exame objectivo não apresentava outras alterações. Analiticamente de destacar: velocidade de sedimentação na $1^{a}$ hora normal, função renal e ionograma normais, proteinograma electroforético sem alterações, transaminases aumentadas duas

\begin{abstract}
Porphyria cutanea tarda results from an enzimatic deficiency in the heme biosynthesis, that may be triggered by iron overload, and is manifested by cutaneous lesions and associated with hepatic disfunction. The authors present a case of a 40-year-old woman with Porphyria cutanea tarda associated with hemochromatosis.

Key words: porphyria cutanea tarda, iron overload, hemochromatosis
\end{abstract}

vezes o normal, LDH 224 U/L (valor normal (N) 100-190 U/L), ferro sérico $163 \mu \mathrm{g} / \mathrm{dL}$ (N 50-170 $\mu \mathrm{g} / \mathrm{dL}$ ), ferritina de $447 \mathrm{ng} / \mathrm{ml}$ (N 20$291 \mathrm{ng} / \mathrm{mL}$ ) e saturação da transferrina de 93\% (N 20-55 \%). As serologias dos vírus da imunodeficiência humana e hepatotrópicos (VHB,VHC,VHA) foram negativas. Doseamento na urina das $24 \mathrm{~h}$ das uroporfirinas: $1089 \mu \mathrm{g} / 24 \mathrm{~h}$ ( $\mathrm{N}<60 \mu \mathrm{g} / 24 \mathrm{~h})$ e nas fezes de coproporfirinas: $37 \mathrm{mcg} / \mathrm{g}(\mathrm{N}<30 \mathrm{mcg} / \mathrm{g}) .0$ doseamento sérico da enzima de conversão da angiotensina (SACE) era de $96 \mathrm{U} / \mathrm{L}$ (N 8-55U/L). 0 estudo da autoimunidade (ANA'S, p-C-ANCA'S, anticorpos anti-Mitocondriais, anticorpos anti-Músculo liso e anticorpos anti-LKM) foi negativo. A ecografia abdominal não apresentava alterações. A TC abdominal mostrava fígado de morfologia e dimensões normais, sem alterações da textura ou lesões nodulares. Realizou biópsia hepática cuja histologia revelou aspectos morfológicos sugestivos de hemocromatose (fibrose portal de intensidade ligeira; necrose marginal de tipo "piece-meal necrosis" de intensidade ligeira; lesões necroinflamatórias intralobulares de intensidade moderada; presença

Figura 1. Lesões cicatriciais no dorso das mãos e antebraços

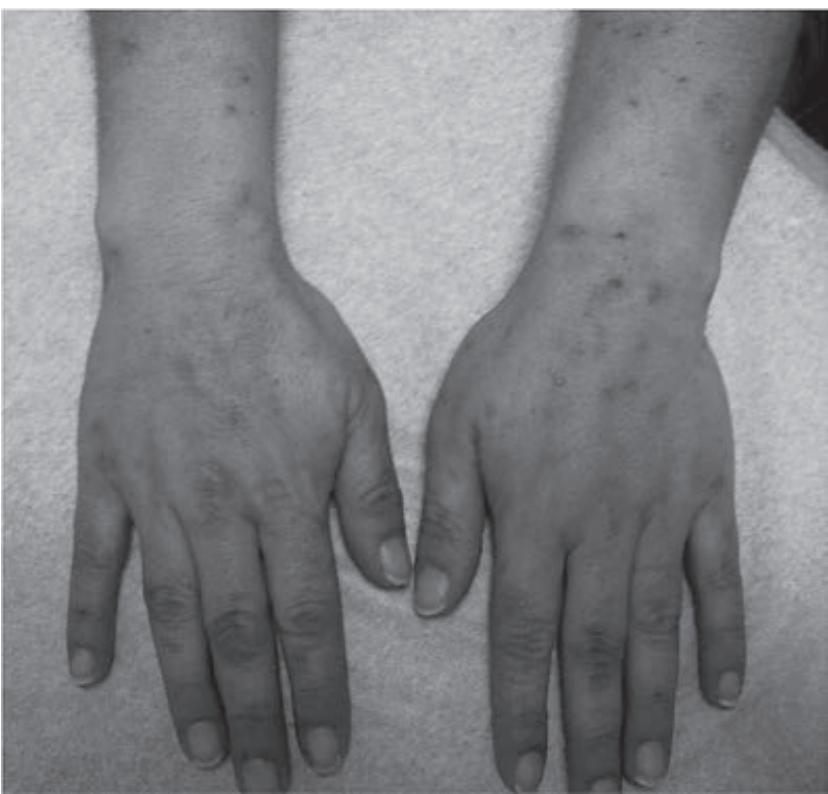


Figura 2. Hiperpigmentação facial

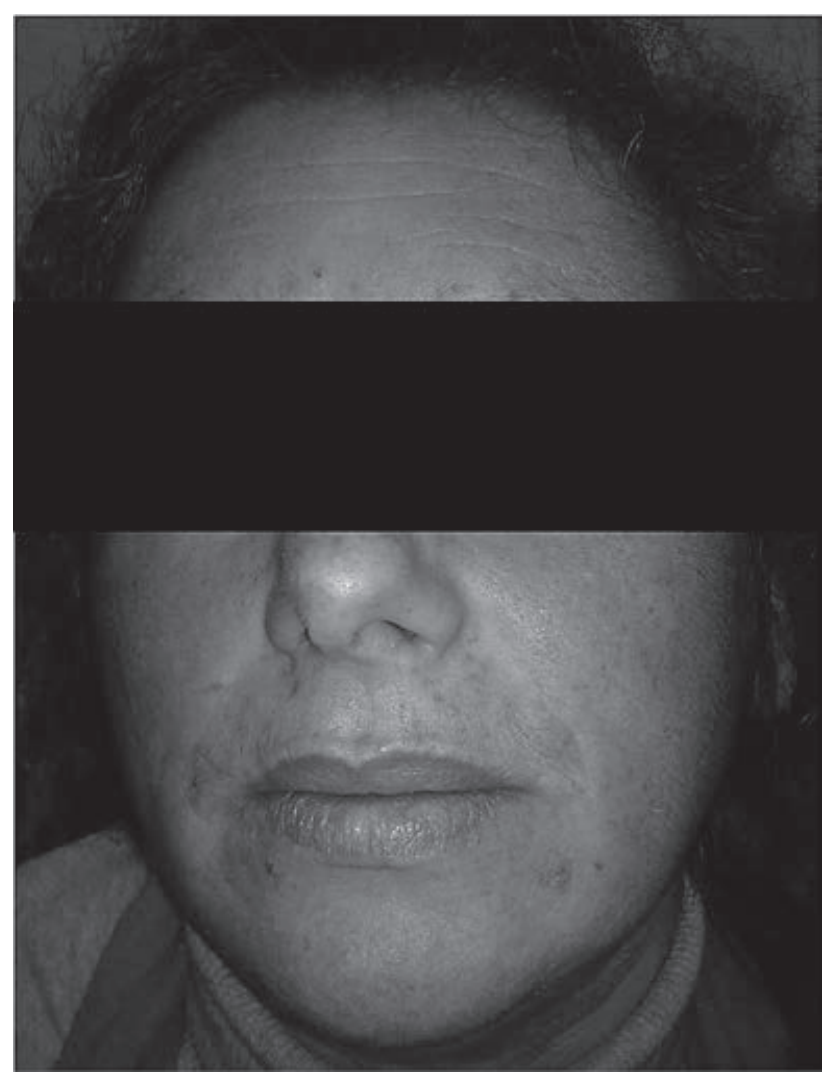

de siderose intra-hepatocitária predominante, mas também nas células de Kupffer) e biópsia cutânea com alterações compatíveis com porfiria cutânea tarda (descolamento subepidérmico, escassez de infiltrado inflamatório e ligeira hialinização de alguns pequenos vasos capilares subjacentes ao descolamento). 0 estudo molecular do gene HFE, revelou uma mutação H63D em homozigotia. A doente iniciou terapêutica com flebotomias regulares, mantendo lesões cicatriciais do dorso das mãos e antebraços, com melhoria da hiperpigmentação cutânea facial.

\section{Discussão}

A PCT é considerada uma doença ferro-dependente, daí que a sua expressão clínica normalmente é observada entre a $3^{\text {a }}$ e $4^{a}$ décadas de vida (como apresentado neste caso clínico), quando já houve tempo necessário para acumulação gradual de ferro ${ }^{3}$. 0 ferro aumenta a produção de uroporfirinas, através da formação de um inibidor competitivo da UROD nas células hepáticas, o uroporfometano, derivado da oxidação parcial do uroporfirinogéneo, através de um mecanismo ferro-dependente ${ }^{1,5}$. Assim se explica a forte associação com doenças em que haja sobrecarga de ferro como a hemocromatose ${ }^{1}$, que deve ser excluída como factor desencadeante da PCT. Há outros factores predisponentes como a infecção pelo vírus da hepatite $C$, infecção pelo vírus da imunodeficiência humana, alcoolismo, uso de estrogénios, hemodiálise, sarcoidose (a doente apresentava SACE elevada, contudo sem outras alterações sugestivas deste diagnóstico) que devem ser excluídos perante a suspeita de PCT ${ }^{1}$.
A hemocromatose hereditária é uma doença genética com herança autossómica recessiva, em que há uma predisposição para aumentar a absorção intestinal de ferro com consequente acumulação de ferro nos tecidos ${ }^{6,7,7,9}$. Laboratorialmente 0 valor de transferrina $>45 \%$ e de ferritina $>200 \mathrm{ng} / \mathrm{mL}$ (como é o caso desta doente) devem levantar a suspeita deste diagnóstico, levando à realização de testes genéticos ${ }^{7}$. 0 papel da biópsia hepática no diagnóstico da hemocromatose hereditária tem vindo a decrescer, com 0 advento da análise do gene HFE, contudo é o método mais fidedigno para estadiamento da doença hepática e está indicada nos doentes com transaminases aumentadas ou ferritina superior a $1000 \mathrm{ng} / \mathrm{mL}^{7}$. A RMN hepática é um método eficaz na medição de ferro intra-hepático, e tem vindo a ser cada vez mais utilizado nos doentes com hemocromatose, com um papel especial na avaliação pós-tratamento, permitindo de uma forma não invasiva monitorizar a sua eficácia e evitar biópsias repetidas ${ }^{10}$.

As mutações mais frequentemente associadas a hemocromatose situam-se no gene HFE, no braço curto do cromossoma 6, C282Y, H63D e S65C. A maioria dos doentes com hemocromatose hereditária apresenta homozigotia C282Y, presente em 80 a 85\% dos doentes típicos ${ }^{7}$. Outras mutações como H63D e S65D, podem causar sobrecarga de ferro (habitualmente mais ligeira) especialmente quando se apresentam na forma de heterozigotia composta com a mutação C282Y, e correspondem a uma minoria de doentes ${ }^{7}$. A mutação H63D em homozigotia (presente nesta doente) está associada ao aumento da saturação da transferrina e da ferritina ${ }^{11}$, contudo não permite 0 diagnóstico definitivo de hemocromatose hereditária. Um estudo realizado com 45 doentes que apresentavam sobrecarga de ferro, conseguiu demonstrar que o genótipo H63D em homozigotia pode ser a causa primária da sobrecarga de ferro ${ }^{11}$, embora alguns autores considerem que esta mutação funciona como um co-factor para o desenvolvimento de hemocromatose quando associada a outras patologias que cursam com sobrecarga de ferro como a PCT7,8.

A presença destas mutações no gene HFE tem sido largamente estudada nos doentes com PCT que apresentam uma elevada frequência da mutação C282Y em homozigotia (entre 11 e $47 \%$ nos estudos realizados na maioria dos países da Europa e EUA) 3,4,12,13. Um estudo no norte da Itália demonstrou também uma incidência significativamente aumentada da mutação H63D nos doentes com PCT ${ }^{3,4,13,14}$. 0 estudo destas mutações nos doentes com PCT para além de estar indicado para rastreio genético de hemocromatose hereditária, tem também implicações no tratamento desta doença.

0 tratamento de $1^{\mathrm{a}}$ linha da PCT consiste em flebotomias de 400-500 ml cada uma a duas semanas até controlo dos sintomas e valores de ferritina inferiores a $25 \mathrm{ng} / \mathrm{mL}^{1}$. Mesmo que a hemocromatose seja assintomática, se associada a PCT, o tratamento com flebotomias está indicado, porque reduz francamente as lesões cutâneas ${ }^{7}$. 
Quando a flebotomia está contraindicada ou não é bem tolerada, a cloroquina em dose baixa (125 mg em dias alternados) pode ser uma alternativa, por aumentar a secreção de porfirinas e inibir a sua síntese ${ }^{1}$, contudo nos doentes com PCT e mutações no gene HFE, não está indicada, por não ser eficaz ${ }^{2,13}$. Outra terapia alternativa são os agentes quelantes do ferro, embora o seu uso ainda não tenha sido avaliado em ensaios clínicos prospectivos ${ }^{1}$. Evitar a exposição solar é fundamental para prevenir as lesões cutâneas na PCT e não esquecer a importância de evitar agressores hepáticos e conhecidos desencadeantes desta doença ${ }^{2}$.

Este caso clínico ilustra a associação entre estas duas patologias ligadas ao ferro, em que a doente procura ajuda pelas lesões cutâneas, laboratorialmente apresenta ligeiras alterações das provas hepáticas (muitas vezes presentes em doentes com PCT pela hemossiderose característica) e alterações da cinética do ferro, que levam ao rastreio genético da hemocromatose. Neste caso a mutação em homozigotia H63D actua como um co-factor associado a PCT, uma doença também relacionada com a sobrecarga de ferro, e permite 0 diagnóstico de hemocromatose. Este rastreio genético é muito importante porque a PCT pode ser a primeira manifestação de uma hemocromatose latente que quanto mais cedo for diagnosticada menor será o atingimento dos órgãos alvo.

\section{Referências bibliográficas}

1. Caballes FR, Sendi $H$, Bonkovsky HL. Hepatitis C, porphyria cutanea tarda and liver iron: an update. Liver Int published online first: 2012. doi:10.1111/j. 1478-3231.2012.02794.x.

2. Frank J, Poblete-Gutiérrez P. Porphyria cutanea tarda - When skin meets liver. Best Pract Res Clin Gastroenterol 2010; 24: 735-745

3. Brady JJ, Jackson HA, Roberts AG, et al. Co-inheritance of mutations in the uroporphyrinogen decarboxylase and hemochromatosis genes accelerates the onset of Porphyria Cutanea Tarda. J Invest Dermatol 2000; 115: 868-874.

4. Vieira FMJ, Nakhle MC, Abrantes-Lemos CP, Cançado ELR, dos Reis VMS. Precipiting factors of Porphyria Cutanea tarda in Brazil emphasis on hemochromatosis hene (HFE) mutations. An Bras Dermatol 2013; 88: 530-540.

5. Bovenschen HJ, Vissers WHPM, Primary hemochromatosis presented by porphyria cutanea tarda: a case report. Cases Journal published online first: 17 June 2009. doi: 10.4076/1757-1626-2-7246.

6. de Geus HRH, Dees A. Sporadic porphyria cutanea tarda due to haemochromatosis. Neth J Med 2006; 64: 307- 309.

7. Bacon, BR, Adams PC, Kowdley KV, Powell LW, Tavill AS. Diagnosis and management of hemochromatosis: 2011 practice guideline by the American Association for the Study of Liver Diseases. Hepatology 2011; 54: 328-343.

8. Vizinho R, Girones C, Loureiro R, Namora J. Hemocromatose hereditária e álcool: sinergismo patogénico - um caso clínico. Med Interna 2009; 14: 156-160.

9. Ramiréz-Santos A, González-Vilas D, Gárcia-Gavin J, Concheiro J, Sánchez-Aguilar D, Toribio J. Porfiria cutánea tarda y hemocromatosis en Espana. Actas Dermosifiliogr 2009; 100: 329-331.

10. Spina JC, del Rivero A, Kidd C, Pietrani M, Savluky L, Garcia RD. Noninvasive assessment of hepatic iron overload in patients with hemochromatosis. Rev Argent Radiol 2013; 77: 139-146.

11. de Diego C, Opazo S, Murga MJ, Mártinez-Castro P. H63D homozygotes with hyperferritinaemia: Is this genotype the primary cause of iron overload?.Eur J Haematol 2007; 78: 66-71.

12. Bulaj ZJ, Philips JD, Ajioka RS, et al. Hemochromatosis genes and other factors contributing to the pathogenesis of porphyria cutanea tarda. Blood 2000; 95: 15651571.

13. Stolzel U, Kostler E, Schuppan D, et al. Hemochromatosis (HFE) gene mutations and response to chloroquine in porphyria cutanea tarda. Arch Dermatol 2003; 139: 309313.

14. Sampietro M, Piperno A, Lupica L, et al. High prevalence of the His63Asp HFE mutation in Italian patients with porphyria cutanea tarda. Hepatology 1998; 27: 181-184. 